\title{
Hip and Knee Dislocations in Extreme Sports: A Six Year National Epidemiologic Study
}

\author{
Vani Sabesan ${ }^{1 *}$, Daniel J Lombardo ${ }^{1}$, Vinay Sharma ${ }^{2}$ and Tom Valikodath ${ }^{3}$ \\ ${ }^{1}$ Department of Orthopaedic Surgery, Wayne State University School of Medicine, MI, USA \\ ${ }^{2}$ Department of Orthopaedic Surgery, Western Michigan University Homer Stryker MD School of Medicine, Kalamazoo, MI, USA \\ ${ }^{3}$ Michigan State University College of Human Medicine, Grand Rapids, MI, USA
}

Received: December 31, 2014; Accepted: March 09, 2015; Published: April 16, 2015

*Corresponding author: Vani Sabesan, Associate Professor, Department of Orthopaedic Surgery, Wayne State University School of Medicine, 10000 Telegraph Road, Taylor MI, USA 48180, Tel: 313-375-7218; Email: vsabesan@med.wayne.edu

\begin{abstract}
Objectives: Participation in extreme sports has been rapidly increasing in the United States. These sports are associated with a significant risk of injury and even mortality. Hip and knee dislocations represent high impact injuries with potentially serious complications if not treated promptly. There is currently little literature describing the epidemiology of these injuries in extreme sports. The purpose of this investigation is to evaluate the incidence rates of hip and knee dislocations in 7 popular extreme sports using a publicly available database.
\end{abstract}

Methods: The National Electronic Injury Surveillance System was used to determine estimated numbers of hip and knee dislocations in 7 extreme sports, from 2007-2012. The Outdoor Foundation data was used to determine participation in these sports. Incidence rates for the various injuries were calculated.

Results: There were 9,369.30 estimated knee dislocations and 742.02 estimated hip over this study period. The incidence rates of knee and hip dislocations for all seven sports were 29.12 and 2.09 per 1 million person-year. These injuries were more common among males, and most occurred in participants between 10-19 years old Snow skiing and snowboarding had the highest rates of knee and hip dislocations respectively.

Conclusions: This study provides baseline data for hip and knee dislocations in participants of extreme sports. These injuries occurred most commonly in males and 10-19 year olds. Awareness of these injuries among extreme sports participants is important as they represent serious injuries, with potentially devastating complications if not managed promptly and properly.

Keywords: Extreme sports; hip dislocations; knee dislocation; epidemiology

\section{Introduction}

Extreme sports participation has continued to increase over the last few decades, with the top 5 extreme sports boasting over 40,000,000 U.S. participants in 2010, according to industry reports [1]. The majority of extreme sports are high-energy, highspeed, high-risk activities [2] that may result in injuries like hip or knee dislocations that are a rare occurrence in the overall US population. Growing popularity of extreme sports participation among amateur athletes, and the advent of extreme sports competitions (X-Games, Olympics), challenge participants to push their physical limits which may lead to increased number of injuries not seen in more traditional recreational sports. The medical consequences of lower extremity joint dislocations can be life altering for these participants.

Hip and knee dislocations require large forces upon impact, and have historically been associated with high-velocity motor vehicle collisions [3-5]. Knee dislocations are typically identified by complete disruption of the integrity of the tibio-femoral articulation, and often have a range of associated vascular and neurological injuries [6-8]. Hip dislocations require even higher forces than knee dislocations and are typically less common than knee dislocations [9]. Similar to knee dislocations a number of complications can be seen and are associated with these injuries $[10,11]$.

With participation in extreme sports increasing in the U.S. especially among young adults, understanding the epidemiology of extreme sports injuries is important for the medical community and serves as a public service. Although rare injuries in the US population, we hypothesized an increased occurrence of hip and knee dislocations in the extreme sports participants. The purpose of this retrospective study was to describe the frequency and distribution of hip and knee dislocations in seven extreme sports over a six-year timespan from January 2007 to December 2012.

\section{Methods}

This descriptive epidemiological study was exempted from Institutional Review Board review. A publically available de-identified database was used and all appropriate ethical standards were followed. We obtained data from the Consumer Product Safety Commission's (CPSC) National Electronic Injury Surveillance System (NEISS). The NEISS is a national probability sample of 100 hospitals in the U.S. and its territories [12]. A large number of these hospitals see less than 16,830 visits per year (47), while 23 hospitals see more than 41,131 patients for year. Of the 46 participating trauma hospitals, 19 are Level 
I trauma centers with the remainder being evenly split among Levels II, III, and IV centers. These distributions demonstrate the wide representation of different hospitals inherent to this database. Patient information is collected from each NEISS hospital for every emergency visit involving an injury associated with consumer products, (i.e. sporting equipment). The clinician generated emergency department records of all injuries at each participating hospital are carefully evaluated by a hospital determined NEISS coordinator, and codes are assigned specific to the NEISS regarding product involved, diagnosis and body part affected. The database is updated daily and missing information if collected via phone interviews. Patient information including age, gender, race, location of incident, and disposition of care is also recorded for each case in the sample. There also is a free text narrative description of select cases included in this database. Each case in the NEISS sample includes a weighting value based on total annual visits at the particular emergency department from which the case was observed. These values allow for weighted estimates of injuries treated in emergency departments nationwide annually. The sampling procedure and the statistical basis for calculation of national estimates based upon the NEISS data is a validated, well described approach.

Injuries associated with seven extreme sports were identified using the consumer product codes from the NEISS database: snowboarding (5031), snowmobiling (1290), surfing (1261), skateboarding (1333), snow skiing (3283), water skiing (1264), and roller-skating (3216). Snow skiing included injuries related to downhill skiing, cross-country skiing, ski jacks, ski lifts, and snowshoes.

Information from the NEISS database was collected in oneyear intervals from January 1, 2007 to December 31, 2012. NEISS specific codes for a diagnosis of "dislocation" (55) and body region were used (lower trunk: 79, knee: 35) for each of the seven sports. The narrative descriptions of 308 cases were screened individually to exclude patellar dislocations. Twentytwo cases were specifically excluded for being described as patellar dislocations, therefore resulting in 286 cases of true knee dislocations. We believe that the narrative description of the remaining cases was specific enough to effectively rule out patella dislocations. The sampling weights, which are assigned to each injury case through the NEISS, were summed to provide national estimates for the different injuries.

Participation figures for the seven extreme sports were collected from annual outdoor recreation participation reports released by The Outdoor Foundation. This organization conducts an annual survey of over 30,000 individuals throughout the United States in order to quantify participation in various sports. Similar to the NEISS, they utilize a validated weighting technique to balance the data in order to reflect participation in the entire US population [13]. The participation numbers acquired from the Outdoor Foundation were used to estimate incidence rates for an extreme sport population.

Incidence rates were calculated as the number of estimated hip and knee dislocations using the NEISS weighted estimates divided by extreme sports population reported by the Outdoor
Foundation Report. Data was not publically available to calculate incidence rates for gender and age. Incidence rate ratios were used to compare the rates for the sports using the sport with the lowest incidence as a reference.

\section{Results}

There was a weighted estimate of 9,369.3 knee dislocations and a weighted estimate of 742.02 hip dislocations over this 6 year time period. Men accounted for $60.26 \%$ of all injures and women for $39.74 \%$ of all injuries. The majority of dislocations occurred in the 10-19 year old age group, after which the number of injuries decreased with age. Regression analysis of total injuries per year showed that the injuries did increase over the time period (Figure 1) $(\mathrm{R}=0.71)$.

Knee and hip dislocations for individual sports are summarized in Tables 1 and 2. Participation rates from The Outdoor Foundation are summarized in Table 3. Snow skiing had the highest estimated number of both knee and hip dislocations (Tables 1,2).

The incidence rate of knee dislocations for all seven sports over this time period was 29.12 per 1 million person-year and 2.09 per 1 million person-years for hip dislocations (Tables 1,2 ).

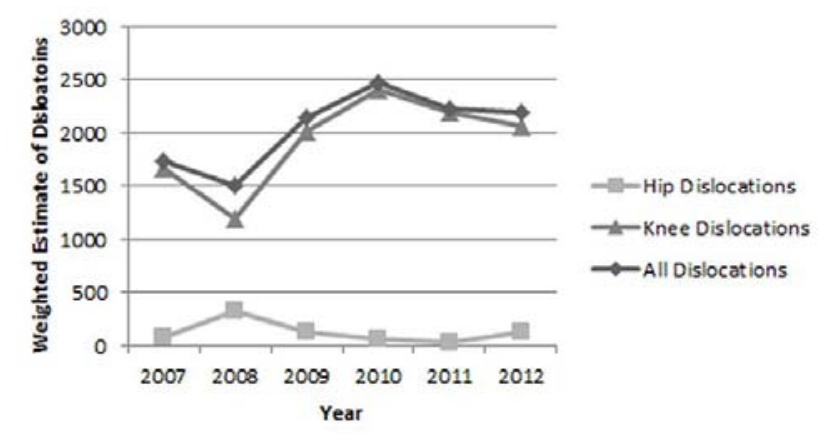

Figure 1: Weighted estimates of hip and knee dislocations in extreme sports by year.

Table 1: Knee dislocation, national weighted estimates of injuries, and incidence rates from 2007-2012. Incidences are in 1 million patientyears. IRR= Incidence Rate Ratio, based on lowest incidence sport.

\begin{tabular}{|c|c|c|c|}
\hline & $\begin{array}{c}\text { National } \\
\text { Estimate of } \\
\text { Injuries }\end{array}$ & Incidence Rate & IRR \\
\hline $\begin{array}{c}\text { Water Skiing and } \\
\text { Wakeboarding }\end{array}$ & 248.25 & 4.13 & 1.00 \\
\hline Snowmobiling & 154.51 & 5.73 & 1.39 \\
\hline Surfing & 374.96 & 24.88 & 6.03 \\
\hline Roller-skating & $1,245.40$ & 26.16 & 6.34 \\
\hline Snowboarding & $1,547.15$ & 34.73 & 8.42 \\
\hline Skateboarding & $1,742.03$ & 40.65 & 9.85 \\
\hline Snow Skiing & $4,057.00$ & 47.96 & 11.62 \\
\hline TOTAL & $9,369.30$ & 29.12 & \\
\hline
\end{tabular}


The highest incidence rate of knee dislocations in participants of extreme sports occurred in snow skiing (Table 1). The highest incidence rate of hip dislocations in participants of extreme sports occurred in snowboarding (Table 2).

Participants of winter extreme sports had a higher average incidence rate for both hip and knee dislocations. Participants in winter extreme sports had a knee dislocation incidence rate of 36.89 per 1 million person-year dislocations per 1 million patient-years, compared to 21.79 for participants of the summer sports (IRR $=1.69$ ). Likewise, winter extreme sports participants had an average incidence rate of 2.37 per 1 million person-year hip dislocations compared to 1.67 for summer sports participants $(\operatorname{IRR}=1.42)$.

Hip and knee dislocations were more common among males than females in the eight studied sports, with males accounted for $60.26 \%$ of all dislocations. Despite the overall preponderance of male knee dislocations, female knee dislocations outnumbered males in snow skiing, roller-skating, and snowmobiling (Table 3).

The occurrence of lower joint dislocations varied for different age groups. The highest occurrence of hip and knee dislocations in extreme sports was in the ten to nineteen years old group (38.7\% of all injuries). The 20-29 year old group had the second highest proportion of injuries (23.2\%). Other than the 0-9 year old age group with had relatively few injuries $(0.50 \%)$, the amount of injuries decreased with age (Figure 2).

Table 2: Hip dislocation, national weighted estimates of injuries, and incidence rates from 2007-2012. Incidences are in 1 million patientyears. There were no reported hip dislocations for surfing or rollerskating. IRR= Incidence Rate Ratio, based on lowest incidence sport.

\begin{tabular}{|c|c|c|c|}
\hline & $\begin{array}{c}\text { National Estimate } \\
\text { of Injuries }\end{array}$ & Incidence & IRR \\
\hline Waterskiing & 70.28 & 1.17 & 1.00 \\
\hline Snowmobiling & 31.58 & 1.17 & 1.00 \\
\hline Snow Skiing & 195.18 & 2.31 & 1.98 \\
\hline Skateboarding & 102.16 & 2.38 & 2.04 \\
\hline Snowboarding & 143.47 & 3.22 & 2.76 \\
\hline Dirt Biking & 199.35 & 4.60 & 3.94 \\
\hline Total & 742.02 & 2.09 & \\
\hline
\end{tabular}

Table 3: Weighted estimates of knee dislocations in extreme sports from 2007-2012 by gender.

\begin{tabular}{|c|c|c|}
\hline & Male & Female \\
\hline Dirt Biking & $1,839.64$ & 320.31 \\
\hline Water Skiing and Wakeboarding & 216.38 & 31.87 \\
\hline Surfing & 256.58 & 118.38 \\
\hline Snowmobiling & 46.47 & 108.38 \\
\hline Snow skiing & $1,568.08$ & $2,488.92$ \\
\hline Snowboarding & $1,218.43$ & 328.71 \\
\hline Skateboarding & $1,589.82$ & 152.21 \\
\hline Roller-skating & 149.15 & $1,096.25$ \\
\hline
\end{tabular}

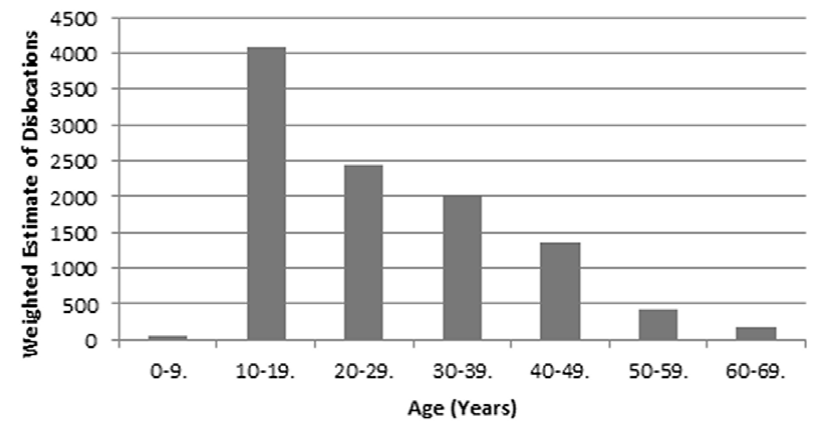

Figure 2: Weighted estimates of hip and knee dislocations in extreme sports by age groups.

\section{Discussion}

Hip and knee dislocations are high energy and high impact injuries that can be devastating to participants at any level. Knee dislocations are limb threatening injuries because of the association with vascular injuries, which is thought to occur in $10-40 \%$ of all knee dislocations and is often associated with poor outcomes and high rates of amputation [14]. Knee dislocation by definition involves damage to multiple ligaments of the knee, resulting in joint instability, limitation in return to sports and long term disability [15-17]. Hip dislocations are another orthopedic emergency, and require early reduction to prevent avascular necrosis of the humeral head which can cause pain, surgical interventions and long term disability $[4,18,19]$. These injuries are most often seen in motor vehicle collisions and are typically associated with other injuries, such as acetabular and pelvis fractures [20]. With many of these extreme sports occurring in remote areas, it is easy to imagine how such injuries requiring emergent treatment could be associated with poor outcomes. The purpose of this study was to provide previously unknown data and establish demographic and incidence rates of hip and knee dislocations for extreme sports participants in the US using the NEISS database.

Overall, extreme sport participants are more likely to dislocate their knee than their hip. Snow skiing had the greatest incidence rate of knee dislocations and snowboarding had the highest incidence rate of hip dislocations among extreme sports participants. The majority of injuries occurred in the 10-19 year old age group. While this may be related to higher participation rates in this age group, it is clear that age is also a risk factor for these types of injuries. These findings highlight the areas in greatest need of improved protection due to their increased risk.

Overall there was a higher rate of hip and knee dislocations in males compared to females. For the majority of sports examined males had a greater numbers of knee dislocations except in snow skiing, roller-skating, and snowmobiling. These findings may provide insight to emphasize better gender specific safety equipment and programs for male participants in extreme sports. A limitation of this conclusion is that the higher number of injuries may be associated with higher participation rates among men. 
The limitations of this study involve those inherent to the NEISS and Outdoor Foundation database reporting. This includes injuries being inaccurately or incorrectly entered due to poor use or interpretation of the specific codes. Additionally, due to how the NEISS codes certain sports, injury estimates may include more than just injuries due to that sport, resulting in inflation of the number of reported injuries. In addition, potential misclassifications of less serious injuries for dislocations may have occurred in the database that could our results.

\section{Conclusion}

This study highlights the incidence rates of hip and knee dislocations in participants of seven popular extreme sports using the NEISS database. The remote areas in which many extreme sports occur and the need for immediate treatment of many of these injuries present a unique problem. Even more, these injuries can potentially have severe complications resulting in impaired function and decreased quality of life. It is important that this problem be recognized and that those involved in extreme sports adhere to regulations and use of recommended protective equipment to better insure the safety of these athletes. We believe that this database can be continually used to monitor the rates of these injuries among extreme sports participants to reassess and future changes or improvements in injury prevention

\section{References}

1. Miller M. Extreme sports surfing to success. BBC Business News 2010 March 25, 2014 [cited 2014 March 25]; Available from: http://www. bbc.com/news/10130842.

2. Palmer C. 'Shit Happens': The Selling of Risk in Extreme Sport. Aust J Anthropol. 2002; 13(3):323-36. doi: 10.1111/j.1835-9310.2002. tb00213.x

3. Brautigan B, Johnson DL. The epidemiology of knee dislocations. Clin Sports Med. 2000; 19(3):387-97.

4. Clegg TE, Roberts CS, Greene JW, Prather BA. Hip dislocationsepidemiology, treatment, and outcomes. Injury. 2010; 41(4):329-34. doi: 10.1016/j.injury.2009.08.007

5. Colen S, van den Bekerom MP, Truijen J. High-energy bilateral knee dislocations in a young man: a case report. J Orthop Surg (Hong Kong). 2013; 21(3):396-400

6. Nicandri GT, Dunbar RP, Wahl CJ. Are evidence-based protocols which identify vascular injury associated with knee dislocation underutilized? Knee Surg Sports Traumatol Arthrosc. 2010. 18(8): p. 1005-12. doi: 10.1007/s00167-009-0918-6.

7. Georgiadis AG, Mohammad FH, Mizerik KT, Nypaver TJ, Shepard AD Changing presentation of knee dislocation and vascular injury from high-energy trauma to low-energy falls in the morbidly obese. J Vasc Surg. 2013; 57(5):1196-203. doi: 10.1016/j.jvs.2012.11.067.

8. Johnson ME, Foster L, DeLee JC. Neurologic and vascular injuries associated with knee ligament injuries. Am J Sports Med. 2008; 36(12):2448-62. doi: 10.1177/0363546508325669.

9. Fairbairn KJ, Mulligan ME, Murphey MD, Resnik CS. Gas bubbles in the hip joint on CT: an indication of recent dislocation. AJR Am J Roentgenol. 1995; 164(4):931-4.

10. Ishimaru D, Ogawa H, Wakahara K, Sumi H, Sumi Y, Shimizu $\mathrm{K}$. Hip pads reduce the overall risk of injuries in recreational snowboarders. Br J Sports Med. 2012; 46(15):1055-8. doi: 10.1136/ bjsports-2012-091204.

11.Yue JJ, Sontich JK, Miron SD, Peljovich AE, Wilber JH, Yue DN, et al., Blood flow changes to the femoral head after acetabular fracture or dislocation in the acute injury and perioperative periods. J Orthop Trauma. 2001; 15(3):170-6.

12.US Consumer Product Safety Commission. The National Electronic Injury Surveillance System (NEISS). 2000. Available from: http:// www.cpsc.gov/en/Safety-Education/Safety-Guides/GeneralInformation/National-Electronic-Injury-Surveillance-System-NEISS/.

13. Outdoor Foundation. 2014 Outdoor Recreation Participation Topline Report. 2014. Available from: http://www.outdoorfoundation.org/ research.participation.2014.topline.html.

14. Stannard JP, Sheils TM, Lopez-Ben RR, McGwin G Jr, Robinson JT, Volgas DA. Vascular injuries in knee dislocations: the role of physical examination in determining the need for arteriography. J Bone Joint Surg Am. 2004; 86-A(5):910-5.

15.Gelber AC, Hochberg MC, Mead LA, Wang NY, Wigley FM, Klag MJ. Joint injury in young adults and risk for subsequent knee and hip osteoarthritis. Ann Intern Med. 2000; 133(5):321-8.

16.Lohmander LS, Englund PM, Dahl LL, Roos EM. The long-term consequence of anterior cruciate ligament and meniscus injuries: osteoarthritis. Am J Sports Med. 2007; 35(10):1756-69.

17. Peskun, CJ, Whelan DB. Outcomes of operative and nonoperative treatment of multiligament knee injuries: an evidence-based review. Sports Med Arthrosc. 2011; 19(2):167-73. doi: 10.1097/ JSA.0b013e3182107d5f.

18. Sahin, V, Karakaș ES, Aksu S, Atlihan D, Turk CY, Halici M. Traumatic dislocation and fracture-dislocation of the hip: a long-term follow-up study. J Trauma. 2003; 54(3):520-9.

19. Upadhyay SS, Moulton A. The long-term results of traumatic posterior dislocation of the hip. J Bone Joint Surg Br. 1981; 63B(4):548-51.

20. Hak DJ, Goulet JA. Severity of injuries associated with traumatic hip dislocation as a result of motor vehicle collisions. J Trauma. 1999; 47(1):60-3. 